\title{
Article
}

Arq Neuropsiquiatr 2010;68(2):258-262

\section{Amyotrophic lateral sclerosis Prospective study on respiratory parameters}

\author{
Sara Regina Meira Almeida', Luciano Bruno C. Silva², \\ Carlos Alberto M. Guerreiro ${ }^{3}$, Anamarli Nucci ${ }^{4}$
}

\begin{abstract}
Objective: To verify how efficient respiratory parameters are in the follow-up of subjects with amyotrophic lateral sclerosis (ALS) and to observe possible correlations between respiratory and nutritional functions. Method: Sixteen patients with probable or defined ALS were selected and evaluated over eight months using the following respiratory parameters: spirometry, maximum inspiratory pressure (MIP), maximum expiratory pressure (MEP), arterial gasometry and pulse oximetry; and nutritional parameters such as body mass index (BMI) and percentage weight loss. Results: $\mathrm{P}_{\mathrm{a}} \mathrm{CO}_{2}$ was a significant parameter to follow up disease evolution ( $p=0.051$ ). There was significant correlation between MIP and $\operatorname{MEP}(r: 0.83) ; B M I$ and MIP (r: 0.70); BMI and MEP (r: 0.72); pulse oximetry and forced vital capacity ( $r$ : 0.57). Conclusion: $P_{a} \mathrm{CO}_{2}$ was shown to be an efficient and significant parameter in the measurement of respiratory impairment; the correlations among MIP, MEP and BMI indicated that these are significant parameters for periodic clinical evaluation.
\end{abstract}

Key words: amyotrophic lateral sclerosis, maximum inspiratory pressure, maximum expiratory pressure, body mass index.

\section{Esclerose lateral amiotrófica: estudo prospectivo de parâmetros respiratórios}

\section{RESUMO}

Objetivo: Verificar a eficácia dos parâmetros respiratórios na evolução de indivíduos com esclerose lateral amiotrófica (ELA) e identificar possivveis correlações entre função respiratória e nutricional. Método: 16 pacientes com diagnóstico provável ou definido de ELA foram selecionados por critérios definidos e avaliados, durante 8 meses, através de parâmetros respiratórios: espirometria, pressão inspiratória máxima (PIM), pressão expiratória máxima (PEM), gasometria arterial e oximetria de pulso; e parâmetros nutricionais: índice de massa corporal (IMC) e porcentagem de perda de peso. Resultados: $\mathrm{P}_{\mathrm{a}} \mathrm{CO}_{2}$ foi um parâmetro significativo para acompanhar a evolução da doença ( $\left.\mathrm{p}=0.051\right)$. Houve correlação significante entre PIM e PEM (r: 0.83); IMC e PIM (r: 0.70); IMC e PEM (r: 0.72); oximetria de pulso e capacidade vital forçada (r: 0.57). Conclusão: $\mathrm{P}_{\mathrm{a}} \mathrm{CO}_{2}$ foi marcador eficaz e significante para medir o comprometimento respiratório; correlações entre PIM, PEM e IMC indicaram ser bons parâmetros nas avaliações clínicas periódicas. Palavras-chave: esclerose lateral amiotrófica, pressão inspiratória máxima, pressão expiratória máxima, índice de massa corporal.

\section{Correspondence}

Anamarli Nucci

Departamento de Neurologia Universidade de Campinas, UNICAMP 13083-970 Campinas SP - Brasil E-mail: anucci@ni.hc.unicamp.br

\footnotetext{
Support

The study had the support of CAPES

(Comissão de Aperfeiçoamento de Pessoal de Nível Superior)

Received 15 September 2009 Received in final form 26 October 2009 Accepted 10 November 2009
}

Amyotrophic lateral sclerosis (ALS) is a degenerative disease that affects motor neurons in the brain and spinal cord. Clinical characteristics include limb weak- ness, difficulties in swallowing, speaking and breathing ${ }^{1}$.

Bulbar dysfunction, resulting from lesions in either the corticobulbar tract or

'MSc, Physiotherapist, Department of Neurology, School of Medical Sciences, University of Campinas (UNICAMP), Campinas SP, Brazil; ${ }^{2} \mathrm{PhD}$, School of Food Engineering, University of Campinas (UNICAMP), Campinas SP, Brazil. Professor at Federal University of Alfenas (UNIFAL), Alfenas MG, Brazil; ${ }^{3}$ Full Professor, Department of Neurology, School of Medical Sciences, University of Campinas (UNICAMP), Campinas SP, Brazil; ${ }^{4}$ Associate Professor, Department of Neurology, School of Medical Sciences, University of Campinas (UNICAMP), Campinas SP, Brazil. 
motor nuclei, increases the risk of aspiration pneumonia, aggravating the respiratory function, which is sometimes already impaired. Swallowing dysfunction leads to nutritional deficiency and consequently to a morbid spiral that increases respiratory muscle fatigue ${ }^{2}$. Nutritional status is aggravated unless it is routinely monitored in order to identify when a patient shows weight loss and malnutrition $^{3}$. Early intervention helps to delay morbidity.

This study was aimed at evaluating how efficient respiratory parameters are in the assessment of ALS evolution, as well as observing possible correlations between respiratory and nutritional functions.

\section{METHOD}

Patients with defined or probable ALS, according to the revised El Escorial, 19984, were followed up at the outpatient clinic for Neuromuscular Diseases of the University of Campinas (UNICAMP), and participated in a crosssectional study with respiratory and nutritional evaluation (first evaluation) and a longitudinal prospective study for eight months, during which respiratory parameters were observed. All the patients were in use of Riluzole and were sporadic cases. Those patients requiring assisted mechanical ventilation or with a nasogastric tube or gastrotomy at the beginning of the study were excluded.

The ethics committee of the School of Medical Sciences - UNICAMP approved the study and all patients signed an informed consent form (protocol 347/2006).

In the initial evaluation, named the first evaluation, patients were assessed using spirometry; maximum inspiratory pressure (MIP), maximum expiratory pressure (MEP), gasometry and pulse oximetry. Three subsequent evaluations every two months included the same tests, except for spirometry.

Spirometry was carried out in the seated position, and included measurement of forced vital capacity (FVC) and peak expiratory flow (PEF) expressed as percentages of the predicted value, according to sex and age.

Maximum inspiratory pressure and maximum expiratory pressure: MIP and MEP measurements were carried out, in accordance with Black and Hyatt, and based on the residual volume and total pulmonary capacity, respectively, at three consecutive moments, with a 30-second interval between maneuvers. The highest value was considered.

Arterial gasometry: partial arterial oxygen pressure $\left(\mathrm{P}_{\mathrm{a}} \mathrm{O}_{2}\right)<83 \mathrm{mmHg}$ and partial arterial carbonic gas pressure $\left(\mathrm{P}_{\mathrm{a}} \mathrm{CO}_{2}\right)>45 \mathrm{mmHg}$ were considered abnormal ${ }^{6}$.

Pulse oximetry was measured using a Moryia 1001 model oximeter.

Symptoms of respiratory muscle weakness: dyspnoea on exertion, morning headaches, fatigue, disturbed sleep (insomnia, excessive daytime somnolence, nocturia, impatience $)^{7}$.
Body mass index (BMI): BMI=body mass $\mathrm{kg} /$ height $\mathrm{m}^{2}$; a value between 18.5 and $24.9 \mathrm{~kg} / \mathrm{m}^{2}$ was considered normal ${ }^{8}$.

Percentage weight loss (WL\%) was determined by comparing usual and current patient weight. Weight loss of $10 \%$ indicated malnutrition and above $10 \%$ indicated severe malnutrition?.

Body mass index and percentage of weight loss were measured in the first evaluation.

\section{Statistical analysis}

In order to compare the evolution of continuous variables, the analysis of variance (ANOVA) was used for repeated measurements with Rank transformation. Correlations between variables were found using Spearman's coefficient. Values were classified as: 0 to 0.19 - weak correlation; 0.2 to 0.39 - mild correlation; 0.4 to 0.59 - moderate correlation; 0.6 to 0.79 -important correlation; 0.8 to 1 - almost perfect correlation ${ }^{10}$. The Statistical Analysis System (version 9.1.3) and Microcal Origin software (version 5.0) were used. A significance level was $\mathrm{p} \leq 0.05$.

\section{RESULTS}

Table 1 shows the demographic data of the patients; four cases (2, 5, 6 and 9) had predominant bulbar ALS and 12 had predominant appendicular ALS. Thirteen male patients and three females were within normal range of pulmonary function test parameters, pulse oximetry and arterial gasometry. The MIP reached $49 \%$ of what was expected, according to the patients' sex and age and the MEP was 34.7\%, indicating restrictive muscle impairment.

The mean BMI for patients subjected to the test $(n=10)$ was 22.54, which is within normal range, although WL\% indicated that three patients were nutritionally at-risk, five had severe malnutrition and two had gained body mass (patients 1 and 8, Table 1). The mean WL\% was 13.3\%.

Five out of 16 patients evaluated for $\mathrm{P}_{\mathrm{a}} \mathrm{CO}_{2}$ succeeded in carrying out the tests on a continuous basis in the first, second and fourth evaluations. In these patients, the mean values of $\mathrm{P}_{\mathrm{a}} \mathrm{CO}_{2}$ ranged between 34.74 in the first evaluation and $39.12 \mathrm{mmHg}$ in the last one, with statistical relevance ( $\mathrm{p}=0.0513$ ) (Figure). The mean $\mathrm{P}_{\mathrm{a}} \mathrm{O}_{2}$ of these patients ranged between 87.16 in the first evaluation and $89.18 \mathrm{mmHg}$ in the last one, with no statistical relevance $(\mathrm{p}=0.7504)$.

Maximum inspiratory pressure was evaluated four times in $15 / 16$ patients and MEP in 14/16. The MIP mean ranged between $-65.67 \mathrm{cmH}_{2} \mathrm{O}$ (first exam) and -64.33 $\mathrm{cmH}_{2} \mathrm{O}$ (fourth exam); this decrease was not significant $(\mathrm{p}=0.7764)$. The MEP mean ranged between $74.29 \mathrm{cmH}_{2} \mathrm{O}$ and $71.79 \mathrm{cmH}_{2} \mathrm{O}$, also with no significance $(\mathrm{p}=0.7671)$. The MIP and MEP values showed high variability and great standard deviation.

The mean values of pulse oximetry showed slight vari- 
Table 1. Descriptive variables in the first evaluation.

\begin{tabular}{|c|c|c|c|c|c|c|c|c|c|c|c|}
\hline \multirow[b]{2}{*}{ Cases } & \multirow[b]{2}{*}{ Age } & \multirow[b]{2}{*}{ Sex } & \multirow[b]{2}{*}{ MIP } & \multirow[b]{2}{*}{ MEP } & \multirow[b]{2}{*}{ Oxi\% } & \multicolumn{2}{|c|}{ Spirometry } & \multicolumn{2}{|c|}{ Gasometry } & \multirow[b]{2}{*}{ BMI } & \multirow[b]{2}{*}{$\% \mathrm{WL}$} \\
\hline & & & & & & FVC\% & PEF\% & $\mathrm{PaO} 2$ & $\mathrm{PaCO} 2$ & & \\
\hline 1 & 59 & $M$ & -55 & 50 & 97 & 98 & 114 & 93.1 & 34.6 & 25.1 & -15.4 \\
\hline 2 & 40 & F & -10 & nap & 95 & nap & nap & 91.2 & 37.2 & 18.2 & 14.3 \\
\hline 3 & 49 & M & -45 & 40 & 94 & 60 & 59 & 102 & 38.4 & 18.1 & 26.4 \\
\hline 4 & 46 & M & -135 & 130 & 96 & 109 & 103 & 61 & 29.1 & 24.2 & 14.6 \\
\hline 5 & 32 & $\mathrm{~F}$ & -10 & 10 & 86 & 54 & 47 & 134 & 29 & 19.5 & 7.4 \\
\hline 6 & 42 & M & -45 & 30 & 97 & nap & nap & 79 & 37 & 19.9 & 21.8 \\
\hline 7 & 53 & M & -110 & 95 & 98 & 87 & 78 & 85.7 & 30.2 & 27 & 2.1 \\
\hline 8 & 44 & M & -100 & 80 & 99 & 96 & 104 & 89.6 & 35.8 & 24.4 & -1.2 \\
\hline 9 & 37 & M & -35 & 45 & 97 & nap & nap & 92 & 38 & 21.3 & 8.7 \\
\hline 10 & 36 & M & -60 & 80 & 94 & 80 & 95 & 73 & 36 & 27.7 & 11.1 \\
\hline 11 & 52 & M & $\mathrm{np}$ & $\mathrm{np}$ & 96 & $\mathrm{np}$ & $\mathrm{np}$ & 70.7 & 38.6 & - & - \\
\hline 12 & 62 & $\mathrm{~F}$ & -70 & 60 & 92 & 80 & 92 & 75.1 & 33.6 & - & - \\
\hline 13 & 41 & M & -30 & 60 & 96 & 52 & 49 & 75 & 42 & - & - \\
\hline 14 & 49 & M & -110 & 125 & 96 & 91 & 86 & 86.9 & 39.5 & - & - \\
\hline 15 & 43 & M & -45 & 85 & 96 & 102 & 102 & 109 & 33 & - & - \\
\hline 16 & 35 & M & -125 & 150 & 95 & 76 & 73 & $\mathrm{np}$ & $\mathrm{np}$ & - & - \\
\hline Mean & 45 & - & 65.66 & 74.28 & 95.25 & 82.08 & 83.5 & 87.82 & 35.46 & & \\
\hline SD & 8.4 & - & 40.78 & 40.32 & 2.97 & 18.82 & 22.45 & 17.89 & 3.87 & & \\
\hline Median & 44.5 & - & 55 & 70 & 96 & 52 & 47 & 86.9 & 36 & & \\
\hline Min & 32 & - & 10 & 10 & 86 & 83.5 & 89 & 61 & 29 & & \\
\hline Max & 62 & - & 135 & 150 & 99 & 109 & 114 & 134 & 42 & & \\
\hline
\end{tabular}

M: male; F: female; MIP: maximum inspiratory pressure; MEP: maximum expiratory pressure; Oxi: Pulse oximetry; FVC\%: percentage of forced vital capacity; PEF\%: peak expiratory flow percentage; $\mathrm{P}_{\mathrm{a}} \mathrm{O}_{2}$ : partial arterial oxygen pressure; $\mathrm{P}_{\mathrm{a}} \mathrm{CO}_{2}$ : partial arterial carbonic gas pressure; $\mathrm{BMI}$ : body mass index; \%WL: percentage weight loss; nap: not able to perform the test; np: test not performed.

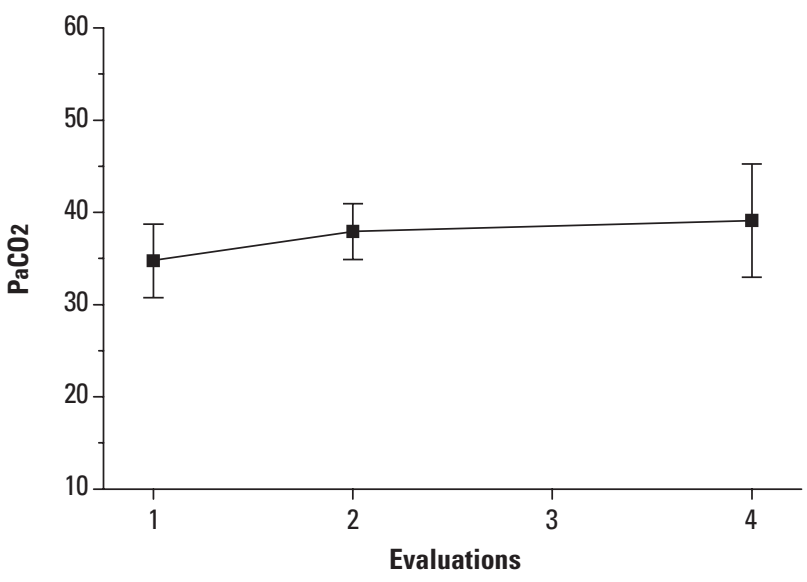

Figure. Mean and standard deviation of $\mathrm{P}_{\mathrm{a}} \mathrm{CO}_{2}$ evolution in the three evaluations. ANOVA Test, $\mathrm{p}$-value $=0.0513$.

ation in the 16 patients: $95.25 \%$ in the first evaluation and 95.13\% in the last one, with no significant statistical variance $(\mathrm{p}=0.1816)$.

Strong correlation between MIP and MEP was observed ( $\mathrm{r}: 0.83500 ; \mathrm{p}=0.0002$ ). Body mass index strongly
Table 2. Spearman's correlation coefficient between respiratory and nutritional parameters

\begin{tabular}{ccccc}
\hline & BMI & $\% W L$ & MIP & MEP \\
\hline $\mathrm{P}_{\mathrm{a}} \mathrm{O}_{2}$ & -0.527 & -0.224 & -0.50222 & -0.44904 \\
$\mathrm{P}_{\mathrm{a}} \mathrm{O}_{2}$ & 0.117 & 0.53 & 0.0672 & 0.1237 \\
$\mathrm{n}$ & 10 & 10 & 14 & 13 \\
$\mathrm{P}_{\mathrm{a}} \mathrm{CO}_{2}$ & -0.418 & -0.491 & -0.26549 & -0.15152 \\
$\mathrm{P}_{\mathrm{a}} \mathrm{CO}_{2}$ & 0.229 & 0.15 & 0.3589 & 0.6212 \\
$\mathrm{n}$ & 10 & 10 & 14 & 13 \\
$\mathrm{Oxi}$ & 0.443 & -0.474 & 0.23863 & 0.13887 \\
$\mathrm{Oxi}$ & 0.2 & 0.166 & 0.3917 & 0.6359 \\
$\mathrm{n}$ & 10 & 10 & 15 & 14 \\
$\mathrm{MIP}$ & 0.70123 & -0.17683 & - & 0.83500 \\
$\mathrm{MIP}$ & 0.0239 & 0.6250 & - & 0.0002 \\
$\mathrm{n}$ & 10 & 10 & - & 14 \\
$\mathrm{MEP}$ & 0.72804 & -0.23431 & - & - \\
$\mathrm{MEP}$ & 0.0262 & 0.5440 & - & - \\
$\mathrm{n}$ & 9 & 9 & - & - \\
\hline
\end{tabular}

$\mathrm{P}_{\mathrm{a}} \mathrm{O}_{2}$ : partial arterial oxygen pressure; $\mathrm{P}_{\mathrm{a}} \mathrm{CO}_{2}$ : partial arterial carbonic gas pressure; Oxi: pulse oximetry; MIP: maximum inspiratory pressure; MEP: maximum expiratory pressure; BMI: body mass index; \%WL: percentage weight loss; n: number of patient 
Table 3. Spearman's correlation coefficient between spirometry and other variables.

\begin{tabular}{ccc}
\hline & FVC\% & PEF\% \\
\hline $\mathrm{MIP}$ & 0.49209 & 0.37544 \\
$\mathrm{MIP}$ & 0.1041 & 0.2291 \\
$\mathrm{MEP}$ & 12 & 12 \\
$\mathrm{MEP}$ & 0.46046 & 0.24562 \\
$\mathrm{n}$ & 0.1320 & 0.4416 \\
$\mathrm{Oxi}$ & 12 & 12 \\
$\mathrm{Oxi}$ & 0.57688 & 0.54199 \\
$\mathrm{n}$ & 0.0496 & 0.0687 \\
$\mathrm{P}_{\mathrm{a}} \mathrm{O}_{2}$ & 12 & 12 \\
$\mathrm{P}_{\mathrm{a}} \mathrm{O}_{2}$ & -0.05467 & -0.15455 \\
$\mathrm{n}$ & 0.8732 & 0.6500 \\
$\mathrm{P}_{\mathrm{a}} \mathrm{CO}_{2}$ & 11 & 11 \\
$\mathrm{P}_{\mathrm{a}} \mathrm{CO}$ & -0.34169 & -0.10909 \\
$\mathrm{n}$ & 0.3037 & 0.7495 \\
$\mathrm{BMl}$ & 11 & 11 \\
$\mathrm{BMl}$ & 0.28571 & 0.42857 \\
$\mathrm{n}$ & 0.5345 & 0.3374 \\
$\% \mathrm{WL}$ & 7 & 7 \\
$\% \mathrm{~nL}$ & -0.32143 & -0.57143 \\
$\mathrm{n}$ & 0.4821 & 0.1802 \\
\hline $\mathrm{n}$ & 7 & 7
\end{tabular}

MIP: maximum inspiratory pressure; MEP: maximum expiratory pressure; Oxi: pulse oximetry; $\mathrm{P}_{2} \mathrm{O}_{2}$ : partial arterial oxygen pressure; $\mathrm{P}_{2} \mathrm{CO}_{2}$ : partial arterial carbonic gas pressure; BMI: body mass index; $\% \mathrm{WL}$ : percentage weight loss; FVC\%: percentage of forced vital capacity; PEF\%: peak expiratory flow percentage; $n$ : number of patient.

correlated with MIP (r: 0.7012; $\mathrm{p}=0.0239)$ and with MEP ( $r: 0.7280 ; \mathrm{p}=0.0262$ ), with no significance in other comparisons (Table 2).

There was moderate significance in correlation between pulse oximetry and FVC values ( $\mathrm{r}: 0.5768 ; \mathrm{p}=0.0496)$, with no significance in other comparisons (Table 3 ).

\section{DISCUSSION}

$\mathrm{P}_{\mathrm{a}} \mathrm{CO}_{2}$ proved to be an efficient indicator in the evaluation of respiratory impairment throughout the eight months. There was an increase in the mean values, even though they remained within the normal range, that is, lower than $45 \mathrm{mmHg}$. Lyall et al. ${ }^{11}$ reported that $\mathrm{P}_{\mathrm{a}} \mathrm{CO}_{2}$ is one of the main parameters used as an indication for starting noninvasive mechanical ventilation in ALS, although it is not very sensitive due to the late manifestation of hypercapnia. It can be supposed that as the disease evolves, hypercapnia may trigger a vicious cycle of pulmonary function worsening and the necessity of ventilation support.

Lyall et al. ${ }^{11}$ recruited 81 patients with ALS to evalu- ate their hypercapnia as a respiratory function complication prognosticator. The $\mathrm{P}_{\mathrm{a}} \mathrm{CO}_{2}$ mean was $41.7 \mathrm{mmHg}$ and only $18 \%$ of the subjects had hypercapnia. The authors reported that in the presence of a mild weakness, $\mathrm{P}_{\mathrm{a}} \mathrm{CO}_{2}$ drops below normal levels and hyperventilation occurs to compensate for alveolar hypoxemia.

According to the American Academy of Neurology there is a lack of evidence of the best parameter to detect respiratory failure. There are no previous studies that evaluate the relationship between respiratory muscle strength and ventilation failure in large samples of ALS patients ${ }^{12}$.

In this study, arterial gasometry and pulse oximetry values remained normal during the eight-month followup. The MIP and MEP values were $60 \%$ below what was expected after the first evaluation, which already indicates the beginning of respiratory muscle impairment ${ }^{5}$ even though the data was not statistically significant.

It is a common belief that $\mathrm{P}_{\mathrm{a}} \mathrm{CO}_{2}$, together with pulmonary hypoventilation signs, may indicate a respiratory impairment throughout time, and that it is an indicator for preventive procedures such as, for instance, the use of noninvasive ventilation support ${ }^{7}$.

Vital capacity is one of the most used clinical tests to monitor pulmonary function ${ }^{13}$. Patients with severe restrictive ventilation impairment resulting from neuromuscular diseases show a more significant reduction of pulmonary volume than maximum pressures. Therefore, vital capacity is a more sensitive measurement in the evaluation of respiratory muscle strength in the advanced stage of these diseases ${ }^{14}$.

Jackson et al. ${ }^{15}$, in their studies on pulmonary function in ALS, reported that most of the patients, even though their FVC was 70\% above expected, had MIP lower than $60 \mathrm{~cm} \mathrm{H}_{2} \mathrm{O}$, which may reflect an early respiratory insufficiency. Our study corroborates that, since the FVC mean was $82 \%$ of the expected value and the MIP mean was $49 \%$ of what was expected.

Pulse oximetry was carried out during outpatient clinical evaluations, and it was not possible to monitor our patients during nights. Even so, there was a positive correlation between oximetry and $\mathrm{FVC}$, demonstrating the importance of evaluating respiratory parameters on a regular basis.

Dysfunction of inspiratory, expiratory and bulbar muscles may result in oxygen desaturation due to hypercapnia, coughing dysfunction and excessive aspiration of saliva. In those conditions, noninvasive ventilation support helps to normalize $\mathrm{P}_{\mathrm{a}} \mathrm{CO}_{2}$ values and oxygen desaturation ${ }^{16}$.

There was no correlation between pulse oximetry and arterial gasometry, probably because patients had not yet shown severe respiratory impairment, with hypercapnia and symptoms of respiratory muscle weakness such as dyspnea on effort, fatigue, morning headache or sleep dis- 
orders. Constant measurement of oxygen saturation is assumed to be necessary to decide what is the ideal moment to start noninvasive mechanical ventilation when a patient complains of what is evidence of nocturnal pulmonary hypoventilation.

Lyall et al. ${ }^{11}$ demonstrated significant correlation between $\mathrm{P}_{\mathrm{a}} \mathrm{CO}_{2}$ and MIP and MEP. The low values obtained in respiratory muscle strength tests led to hypercapnia. Hypercapnia occurs when weakness becomes severe, leading to ventilation failure. As no correlation between these parameters was found, it is assumed that weakness of respiratory muscles in our patients was mild to moderate.

Just like Lechtzin ${ }^{17}$, we assume it is a wise procedure to measure $\mathrm{P}_{\mathrm{a}} \mathrm{CO}_{2}$ when spirometry is unable to explain symptoms of respiratory complications in patients or if they report sleeping difficulties.

The most significant correlation of BMI and respiratory parameters was between MIP and MEP, in which patients with greater weakness and reduced body mass showed reduced respiratory muscular strength. There was no correlation between BMI and spirometry since the patients presented with normal values for FVC and spirometry. This is probably because spirometry is not sensitive enough to evaluate ventilation function in initial or moderate stages of respiratory discomfort, as reported by Schoesmith et al. ${ }^{18}$.

The results found in this study corroborate those obtained by Silva et al. ${ }^{19}$ who also found correlation between BMI and FVC and between BMI and MEP in patients who presented with bulbar ALS. The correlation was strong, even considering MIP and MEP indicators are not a sensitive measure in the evaluation of the respiratory function in these patients, due to oro-pharyngeal weakness, as described by Fitting et al. ${ }^{20}$.

Desport et al. ${ }^{21}$ evaluated nutritional status through the use of BMI in ALS patients. In their study, the survival rate time was shorter in malnourished patients when compared to the group considered as normal. The nutritional status was a decisive factor for survival, as a vital capacity $60 \%$ higher than the expected value. However, both measurements were considered as independent prognostic values.

In the patients that had BMI assessed, the FVC mean was $83.4 \%$ of the predicted value. Only two out of the 10 patients who had their BMI evaluated in the first visit had values below normal. When evaluated by WL\%, five patients showed severe malnutrition, in other words, a loss greater than $10 \%$, according to Mahan and Stump ${ }^{9}$ values. Rio and Cawadias ${ }^{3}$ suggest that body weight to evaluate nutritional status in ALS patients should not be underestimated; however, impaired mobility may be a limitation in the measurement of this parameter. Nutritional support may delay weight loss and muscular atrophy. Studies have demonstrated that body weight loss associ- ated with bulbar changes (dysphagia and breathing) requires early and specific nutritional support ${ }^{22}$.

The intervention of the multidisciplinary team, such as physicians, physiotherapists, nutritionists and speech therapists, is necessary to evaluate the patient as a whole. A more comprehensive healthcare protocol allows the patient an improved quality of life.

In conclusion, $\mathrm{P}_{\mathrm{a}} \mathrm{CO}_{2}$ was shown to be an efficient and significant parameter to in the measurement of respiratory impairment. The correlations among MIP, MEP and BMI indicated that these are significant parameters for periodic clinical evaluation.

\section{REFERENCES}

1. Orrell RW. Understanding the causes of amyotrophic lateral sclerosis. New Eng J Med 2007;357:822-823.

2. Hardiman O. Symptomatic treatment of respiratory and nutritional failure in amyotrophic lateral sclerosis. J Neurol 2000;247:245-251.

3. Rio A, Cawadias E. Nutritional advice and treatment by dietitians to patients with amyotrophic lateral sclerosis/motor neurone disease: a survey of current practice in England, Wales, Northern Ireland and Canada. J Hum Nutr Diet 2007;20:3-13.

4. El Escorial revisited: revisited criteria for the diagnosis of ALS - World Federation of Neurology research group on motor diseases. A consensus conference held at Airlie House. Worrenton 1998:2-4.

5. Black LF, Hyatt RE. Maximal respiratory pressures: normal values and relationship to age and sex. Am Rev Respir Dis 1969;99:696-702.

6. Terzi RGG. Equilíbrio ácido-básico e transporte de oxigênio. São Paulo: Ed Manole, 1992

7. Leigh PN, Abrahams S, Al-Chalabi A, et al. The management of motor neurone disease. J Neurol Neurosurg Psychiatry 2003;74:32-47.

8. Organizacion Mundial de la Salud. Necesidades de energia y proteínas. Informe de uma reunion consultiva conjunta FAO/OMS/UNU de expertos. Genebra, 1985.

9. Mahan K, Stump SE. Krause: alimentos, nutrição e dietoterapia. $11^{\mathrm{a}}$ Ed. São Paulo: Roca, 2005:535-569.

10. Landis JR, Koch GG. The measurement of observer agreement for categorical data. Biometrics 1977;33:159-174.

11. Lyall RA, Donaldson N, Polkey MI, Leigh PN, Moxham J. Respiratory muscle strength and ventilatory failure in amyotrophic lateral sclerosis. Brain 2001; 124:2000-2013

12. Miller RG, Rosenberg JA, Gelinas DF, et al. Practice parameter: the care of the patient with amyotrophic lateral sclerosis (an evidence-based review): report of the Quality Standards Subcommittee of the American Academy of Neurology. Neurology 1999;52:1311-1323.

13. ATS/ERS. American Thoracic Society/European Respiratory Society. ATS/ ERS statement on respiratory muscle testing. Am J Respir Crit Care Med 2002; 166:518-524.

14. Perez T. Neuromuscular disorders: assessment of the respiratory muscles. Rev Neurol 2006:4:437-444.

15. Jackson CE, Rosenfeld J, Moore DH, et al. A preliminary evaluation of a prospective study of pulmonary function studies and symptoms of hypoventilation in ALS/MND patients. J Neurol Sci 2001;191:75-78.

16. Bach JR, Bianchi C, Aufiero E. Oximetry and indications for tracheotomy for amyotrophic lateral sclerosis. Chest 2004;126;1502-1507.

17. Lechtzin N. Respiratory effects of amyotrophic lateral sclerosis: problems and solutions. Respir Care 2006;51:871-881.

18. Shoesmith CL, Findlater K, Rowe A, Strong MJ. Prognosis of amyotrophic lateral sclerosis with respiratory onset. J Neurol Neurosurg Psychiatry 2007;78:629-631.

19. Silva LBC, Mourão LF, Silva AA, et al. Amyotrophic lateral sclerosis: combined nutritional, respiratory and functional assessment. Arq Neuropsiquiatr 2008;66:354-359.

20. Fitting JW, Paillex R, Hirt L, Aebischer P, Schluep M. Sniff nasal pressure: a sensitive respiratory test to assess progression of amyotrophic lateral sclerosis. Ann Neurol 1999;46:887-893.

21. Desport JC, Preux PM, Truong TC, Vallat JM, Sautereau D, Couratier P. Nutritional status is a prognostic factor for survival in ALS patients. Neurology 1999;53:1059-1063.

22. Kasarskis E, Berryman S, Vanderleest JG, Schneider AR, Mcclain CJ. Nutritional status of patients with amyotrophic lateral sclerosis: relation to the proximity of death. Am J Clin Nutr 1996;63:130-137. 